\title{
Textos poéticos sobre la emancipación de la mujer sefardí en el mundo de los Balcanes*
}

\author{
Elena Romero \\ ILC - CSIC, Madrid
}

\section{LA ELECCIÓN DE NOVIO}

Para ilustrar este apartado me valgo de seis textos ${ }^{156}$.

\section{Novio a la moda}

El texto procede de la siguiente fuente única:

- Versión oral de Sará Cohén publicada por Attias Cancionero núm. 23 (pp. 86-87), en letras latinas y con traducción al hebreo.

Canción tradicional de la que Attias dice (p. 87) que las dos primeras estrofas son de otro texto y a las que añade (p. 87) una más, tomada de otra versión de la que no da más datos; en esta edición no tengo en cuenta tales estrofas añadidas. La fecho por aproximación en ca. 1905.

Consta de 5 cuartetas con formulaciones paralelísticas y rima difusa.

$$
\begin{aligned}
& \text { [...] } \\
& 3 \text {-Así yiva el siñor padre, } \\
& \text { así yiva yo con él, } \\
& \text { que me deǰe ver el mundo, } \\
& \text { el amor qué cośa es.- } \\
& 4 \text {-Así yivas tú, mi hija, } \\
& \text { y así yiva yo con ti, } \\
& \text { yo te meteré en escola } \\
& \text { que t'ambeźes cumplición }{ }^{157} \text {.- }
\end{aligned}
$$

*Vid. mi corrección al final de los textos.

${ }^{156}$ A ellos podría añadirse el compuesto por Ŝạic y Gaśóś que publica NAR Sinagogas (pp. 208-209, con traducción al griego), sobre las ansias de casarse con una chica rica.

${ }^{157}$ En su versión al hebreo AtTiAs traduce la palabra por halijot 'normas de comportamiento'. 
5 -Así ỵiva siñor padre, así yiva yo con él, yo no quiero en la escola ni embeźarme cumplición.

6 Así ỵiva siñor padre, así yiva yo con él, que me bušque un mancebico y que sea del felec.-

\section{Las ofertas del padre}

El texto procede de la siguiente fuente única:

- Versión oral de Sofía publicada por Levy Chants II núm. 103 (pp. 89-90), con melodía ${ }^{158}$.

Canción tradicional que fecho por aproximación en ca. 1905. Bunis Voices (pp. 184-185), quien dice que se trata de la adaptación al judeoespañol de una canción turca, publica tres estrofas de una versión diferente.

Consta de 9 estrofas con formulaciones paralelísticas.

1 -Hija mía, ¿comer tú querías?-

-No, siñor padre, no.

El corazón mío, bembrillo podrido, mi papá no sabe el dert mío.-

2 -Hija mía, ¿fostán tú querías?-

-No, siñor padre, no.

El corazón mío, bembrillo podrido, mi papá no sabe el dert mío.-

3 -Hija mía, ¿peine tú querías?-

-No, siñor padre, no.

El corazón mío, bembrillo podrido, mi papá no sabe el dert mío.-

4 -Hija mía, ¿pudra tú querías?-

-No, siñor padre, no.

El corazón mío, bembrillo podrido, mi papá no sabe el dert mío.-

${ }^{158}$ Allí mismo recoge LeVy (núm. 104 pp. 90-91, con melodía) otra versión similar de Sarajevo; en este caso lo que el padre va ofreciendo a su hija son novios de distintas profesiones: sastre (estr. 2), maestro (3), mercader (4), médico (5) y el vecino (6), que es el aceptado. 
5 -Hija mía, ¿calzas tú querías?-

-No, siñor padre, no.

El corazón mío, bembrillo podrido, mi papá no sabe el dert mío.-

6 -Hija mía, ¿calzados tú querías?-

-No, siñor padre, no.

El corazón mío, bembrillo podrido, mi papá no sabe el dert mío.-

7 -Hija mía, ¿manías tú querías?-

-No, siñor padre, no.

El corazón mío, bembrillo podrido, mi papá no sabe el dert mío.-

8 -Hija mía, ¿anillos tú querías?-

-No, siñor padre, no.

El corazón mío, bembrillo podrido, mi papá no sabe el dert mío.-

9 -Hija mía, ¿novio tú querías?-

-¡Sí, siñor padre, sí!

El corazón, mío bembrillo podrido, mi papá ya supo el dert mío.-

\section{Las angustias de un padre}

El texto procede de la siguiente fuente única:

- Versión aljamiada en el manuscrito de Ya‘acob Hazán (Rodas, finales del siglo XIX) f. $3 \mathrm{r}^{159}$.

Canción tradicional publicada también por Attias Cancionero núm. 20 (pp. 82-83), en letras latinas con traducción al hebreo ${ }^{160}$. Siguiendo sus palabras (p. 83) la fecho por aproximación en ca. 1905.

Consta de 4 cuartetas de rima en los pares; tras los vs. $b$ y $d$ de todas las estrofas se intercalan las palabras «amán, amán».

$$
\begin{aligned}
& 1 \text { A la cama me echo } \\
& \text { rog[?] }{ }^{161} \text { que amanezca, }
\end{aligned}
$$

${ }^{159}$ Fecho la canción según las indicaciones de Armistead - Silverman 3 Calas (p. 16 núm. 1 y p. 21), quienes la atribuyen a la mano III del manuscrito.

${ }^{160}$ Señalo en las notas mis diferencias de lectura con Attias.

${ }^{161}$ Ilegible; Atтias lee rogando. 
amán, amán, que venga mi boliśa que me dé pacencia.

Amán, amán ${ }^{162}$.

2 La muchachas de agora

no queren novlios bajos ${ }^{163}$, amán, amán, queren a sus boyaes ${ }^{164}$ sin barba y sin mostacho ${ }^{165}$. Amán, amán.

3 Las muchachas de agora no queren coredores, amán, amán; antes que despośen ya cobran amores.

Amán.

4 Los novlios de agora no toman contado, amán, amán; mercan a las novias con su demaśiado ${ }^{166}$. Amán.

5 A la cama me echo, el cabezal lo mojo, amán, amán; ya no me quedó pestañas en los ojos.

Amán.

${ }^{162}$ A continuación se indica: «que venga 2 većes».

163 AtTias omite bajos; no sé si se refiere a la estatura de los novios o a su extracción social.

${ }^{164}$ Escrito בויאיס; AtTiAs lee boyes, de tc. boy, y traduce 'a su gusto (de ellas)'.

165 Es decir, muy jóvenes.

${ }^{166}$ La palabra está usada como sustantivo y no como adverbio; probablemente hay que ponerla en relación con hb. תוספת toséfet 'adición, suplemento, «lo de demás»', cantidad estipulada en el contrato matrimonial que el marido debe pagar a su mujer en caso de divorcio injustificado y que se entiende como un resarcimiento por la pérdida de su virginidad. Quizá lo que quiere decir el texto es que las mozas no llegan al tálamo en tal estado. 


\section{Las pretensiones de las ricas}

El texto procede de la siguiente fuente única:

- Versión aljamiada publicada en 12 Cantes populares de Sadic y Gaśós ([Salónica ca. 1924]: edición La Vara) pp. 3-4 (Havassy New Texts núm. II).- En portada: «... 3) Pretansiones de la jonés ("Catiá")»; cabecera: «Pretansiones de la jonés, se canta al son del hermośo foxtrot de la opereta "La dansós Catiá"».

Poema inédito de Ŝạic y Gaśóś. Havassy New Texts (p. 48) comenta y publica con traducción al hebreo el último segmento del texto.

Consta de 3 estrofas de 8 versos y rima aaabcccb, seguidas de sendos «Refrén» numerados en arábigos formados por dos bloques de 8 versos que riman cada uno con el mismo sistema que las estrofas.

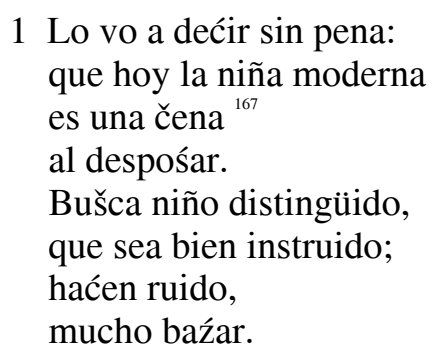

Son ex́iǵentes
si tienen deventes ${ }^{168}$
y meten las mientes
al garḅe, al boy.
Cuando escoǵen
novedades recoǵen ${ }^{169}$,
la ceja encoǵen
si non viene de soy ${ }^{170}$.
Bušcan despiertos
que sean horfentos ${ }^{171}$

${ }^{167}$ NeHAmA s.v. šéna recoge la expresión paralela a la española de fazer šena a uno; es decir, que a la hora de buscar novio, las chicas organizan un buen lío.

${ }^{168}$ Es decir, si la novia tiene dinero se comporta de forma muy exigente.

${ }^{169}$ Entiendo que quiere decir que se informan bien sobre el candidato.

${ }^{170}$ Nehama s.v. soy recoge la expresión venir de soy que traduce 'dériver d'une bonne lignée'.

${ }^{171}$ Nehama s.v. jorfá y jorfénto hace derivar la palabra de hb. חרי 'ח harif 'agudo, listo' y explica fazer jorfot como 'déployer des gestes, se prodiguer en mouvements, en actes soi-disant ingénieux, gracieux [...]' y jorfénto como 'maniéré, guindé, affecté'. 
y que tengan ĝestos, que sepan hablar.

Ellas aĉetan, al bueno rejetan, non lo regretan porque saben bien bailar ${ }^{172}$.

2 Tengo visto más de una, sea blonda, sea bruna, que comió pruna por pretansión.

Le truǰeron novio bueno: porque era poco lleno ${ }^{173}$, era moreno, con instrucción,

non le conviene

y se lo contiene, $\mathrm{y}$ a lo que tiene da mucha valor. Se haće vieja, se pasa pudra ceja ${ }^{174}$, suspira, bosteža y piedre la color.

Novio non topa, destiñe su ropa ${ }^{175}$; porque quiere pompa non topa al par.

Toma un quito o algún afito ${ }^{176}$,

${ }^{172}$ Es decir, desdeñan a un buen chico y no se lamentan de ello porque aquel al que han escogido sabe bailar bien.

${ }^{173}$ Que no sé si se refiere a que era flaco o a que no tenía dinero.

${ }^{174}$ Nehama s.v. púdra recoge la expresión pasar pudra que traduce '[...] embellir par des artifices, dissimuler les défauts, les laideurs'; pero en el verso habríamos esperado «por la ceja», es decir, que se pinta las cejas porque le han emblanquecido.

${ }^{175}$ Es decir, la ropa se le va quedando desteñida, sin color.

176 Aquí debemos entender la palabra como de it. affitto 'afligido, atormentado', es decir, 'persona insoportable', según el sentido que recoge NEHAMA s.v. afíto de 'importunité accablant, ennui, énervement intolérable [...] causée par [...] une présence fastidieuse, exaspérante'. 


$$
\begin{aligned}
& \text { piedre dirito }{ }^{177} \\
& \text { porque preferó parpar. }
\end{aligned}
$$

3 Hay muchos niños fedidos, porque fueron conqueridos, fueron vendidos ${ }^{178}$ por los sermés.

Empiegado de la gruta él escoǵe una bruta cuando le unta muchas draḥmes.

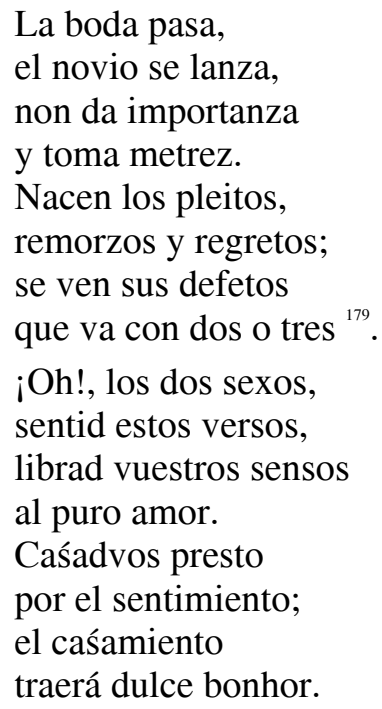

\section{Novios renuentes}

El texto procede de la siguiente fuente única:

- Versión aljamiada publicada en 10 Cantes populares de Sadic y Gaśóś, Cinquena sería (Salónica [ca. 1926]: edición del Riśón, estamparía Beźés) pp. 5-6 (Havassy New Texts núm. V).- En portada: «... 4. No les da el... corazón»; cabecera: «Non les da el... corazón; se canta al son del fox blu "טרילי אגאפי)

\footnotetext{
${ }^{177}$ Lo que ha perdido es el derecho a exigir.

${ }^{178}$ Es decir, se vendieron por lo que se dice luego: el dinero de la dote.

${ }^{179}$ Entiendo que con dos o tres mujeres.
} 
[<Tryly agapy>]" de la opereta "מאקריס קונדוס קיי סינדרופ'אהacrys cwndws qyy syndrwfyá > ]"».

Poema inédito de Ŝạic y Gaśós. Havassy New Texts (p. 49) recoge, comenta y traduce al hebreo el inicio del «Refrén» que sigue a estr. 3 .

Consta de 3 estrofas numeradas en romanos de 6 versos dodecasílabos bimembres y rima $A A B B C C$, seguidas de sendos «Refrén» numerados también en romanos y formados por dos bloques de 8 versos cada uno de rima $a B a B c d c d$.

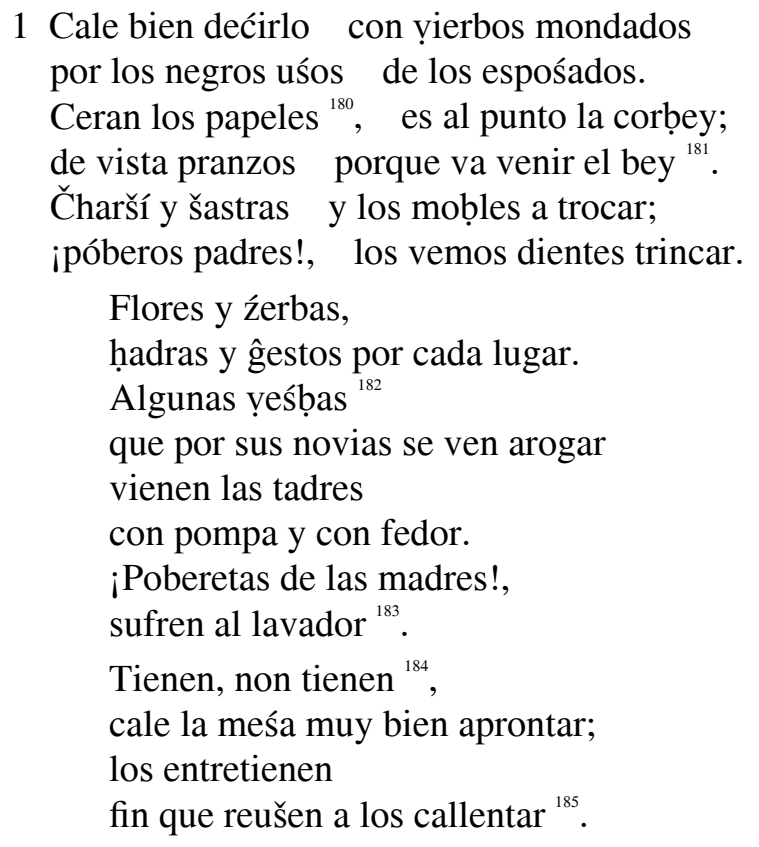

${ }^{180}$ Es decir, apenas firman el acuerdo de boda sucede lo que viene luego.

${ }^{181}$ Es decir, inmediatamente se ponen a organizar grandes banquetes como si fueran a recibir a un bey.

${ }^{182}$ NehAma s.v. bézba ('avispa, abeja') recoge la expresión fazerse bezba que traduce 'insister, revenir à la charge'; por lo que dice en el verso siguiente, tales cargantes parecen ser las novias; sin embargo, también podrían ser los chicos que se plantan todas las tardes en casa de sus novias a merendar o a cenar.

${ }^{183}$ Nehama s.v. lavador explica la palabra 'vaissell sale qu'il faut laver', es decir, que las madres tienen que fregar los cacharros sin que nadie las ayude.

${ }^{184}$ Es decir, los padres, tengan o no tengan dinero.

${ }^{185}$ Es decir, los sufridos padres se esfuerzan por crear un ambiente acogedor. 
Los dejan solos

para los encorajar, para embeźar los rolos ${ }^{186}$ y sin los deranjar.

2 Las novias, vestidas, metidas al tiro, fin versen en esto se haćen un giro ${ }^{187}$. Hay ciertos novios no se pueden somportar, que con sus hecha non se saben comportar. Los genitores sufren y non pueden ver, se haćen bobos y neglijan sus dober ${ }^{188}$.

¿Qué negros uśos!, los negros tiempos los hace temblar; ven los aḅuśos, los poberetos non pueden hablar.

Culpan las novias ${ }^{189}$ que, cuando los ven tadrar, con los pieśes haćen foyas ${ }^{190}$, no se saben guadrar.

Hay muchos novios, hay muchos tipos que toman plaćer; bušcan embrolios, porque se hartan, se haćen beźer, Dićen dos yierbos: «no me dio el corazón» ${ }^{191}$; ya vimos muchos mancebos fuyir d'esta fasón.

3 Como veš, las novias non tienen defensa porque ciertos novios non tienen vergüenza.

\footnotetext{
${ }^{186}$ Quizá quiera decir para que se vayan conociendo.

${ }^{187}$ Es decir, las novias, hasta que se ven en semejante situación, de puros nervios adelgazan como si fueran arenques.

${ }^{188}$ Es decir, los padres, con tal de no ahuyentar al novio, no hacen lo que tienen que hacer, que es vigilarlos.

${ }^{189}$ Es decir, las novias son las culpables de tal situación.

${ }^{190}$ Es decir, cuando los novios tardan en aparecer, se ponen tan nerviosas que hacen agujeros en el suelo de tanto golpear con los pies.

${ }^{191}$ Con tales palabras deshacen todos los acuerdos de boda y desaparecen.
} 
Cerca la boda ya se echan a'nramar ${ }^{192}$, les dan el dopio ${ }^{193}$ para los haćer calmar; ex́iǵen cośas que no hay en el papel ${ }^{194}$ : gastes de boda con viaje y hotel...

Niñas, pensando ${ }^{195}$,

mirando antes de vos espośar; analiźando, tened coraǵe de los refuśar a el mancebo que haće mucho baźar, que derite vuestro sebo antes de se caśar.

Non deš al punto

lo que guadráš como un capital ${ }^{196}$.

Si es manuto ${ }^{197}$,

haćed un gesto, mostrad el portal ${ }^{198}$; esto vos salva

a vos y vuestra honor.

Mi consejo, si vos ḥarba, es por vuestro bonhor.

\section{Planes de boda}

El texto procede de la siguiente fuente única:

- Versión aljamiada publicada en el periódico de Constantinopla El Juguetón 19/35 (23 ḥešván 5688 / 18 nov. 1927) p. 2a-b.- Cabecera: «Despośorios del felec: Programa de un joven y una demuaśel».

${ }^{192}$ Es decir, cuando se aproxima la fecha fijada para la boda, empiezan a poner problemas y a amenazar con romper el compromiso.

${ }^{193}$ Escrito al dopio. Es decir, para calmarlos, les dan el doble de lo que antes les habían ofrecido de dote.

${ }^{194}$ Escrito papig; se refiere al contrato de esponsales.

${ }^{195}$ Este gerundio y los siguientes con valor de imperativo.

${ }^{196}$ Es decir, su virginidad.

${ }^{197}$ Que Nehama s.v. manúto explica 'brutal, qui a l'habitude de frapper, qui passe vite des paroles aux coups [...]'.

${ }^{198}$ Es decir, ponedlos en la calle. 
Poema inédito firmado por el pseudónimo «sudito 'Aní» tras la cabecera; consta de 27 estrofas de 4 versos formadas por pareados encadenados.

Lo que diće el joven

1 Yo estó para espośar y en presto quero caśar; ma para tomar una ${ }^{199}$ novia a mi lado quero 20 mil liras de contado.

2 Esta suma cale que me venga y en mi pecho cale que las tenga.

Por tanto, sentid un poco mi propośición, no vo haćer en nada questión.

3 No importa si la novia es morena, basta que ella sea llena y tenga en la cara un poco de nur y para frecuentar algo de šiúr ${ }^{200}$.

4 Si es carapicada ${ }^{201}$, no v'a haćer atanción, vos juro que la vo amar con pasión, porque los 20 mil traen riqueźa y en la vida muncha fineźa.

5 Si es ciega de un ojo, la vo acceptar, porque las 20 mil me van a hartar y me van a llamar todos guebir ande vo ir y venir.

6 Si es cojica, la tomaré al brazo, anque munchas većes me veré canso; ma las 20 mil tomarán mi canseria y harán olvidar mi laćeria.

7 No me importa también si es cholaca, basta que sea godra como la vaca; la gente, en hablando, me van avergüenzar, ma al cabo se van a cansar.

8 Sodra si es, a gritos le hablaré, al bodre de la oreja siempre le gritaré;

${ }^{199}$ La palabra una repetida.

${ }^{200}$ Escrito ש'יאור ši שיעור (cfr. hr 'cantidad, medida'); es decir, que tenga dinero para pagar cuando salgan juntos.

${ }^{201}$ Es decir, con la cara picada de marcas de viruela. 
de las 20 mil siempre me acodraré y nunca por esto cavśo haré.

9 Corcobada mismo tomo, basta que sea naźic, anque munchos me dirán que tomí grande caźic, las 20 mil ya tapan todo para responder a cada uno de un modo.

$10 \mathrm{Be}[] \mathrm{uta}^{202}$ si es, la tomaré con buenas, le fregaré de vez en cuando las venas y nunca la bušcaré a deśdeñar, porque con las vente mil me puede hararbar.

11 Budaca $^{203}$ si es, me haré del lonso ${ }^{204}$, cada noche me mostraré del canso ${ }^{205}$; cuando despierto, cuando dormido, vendré cada noche muy tadre al nido.

12 En fin, si me salió niervośa, dar[é] de pasada ${ }^{206}$ en cada cośa y le daré parás para jugar ${ }^{207}$, para que sorete ${ }^{208}$ en cada lugar.

13 Este es mi programa de caśar que todos se pueden baśar ${ }^{209}$ y cuando toparé una novia semejante la arecibiré con muncho cante.

14 La miraré como una rośa y la haré siempre ḥenośa;

${ }^{202} \mathrm{El}$ mal estado de la fotocopia que manejo me impide leer bien la palabra, pero lo que sí puedo afirmar es que la bet inicial no lleva tilde. En cualquier caso, por lo que se dice en el verso siguiente debe entenderse como 'varicosa'.

${ }^{203}$ Cfr. tc. budak 'pronunciación gutural de la $r$ ', es decir, 'tartajosa o gangosa'.

${ }^{204}$ Es decir, me haré el bobo.

${ }^{205}$ Es decir, me haré el cansado.

${ }^{206}$ Nehama s.v. pasáda recoge la expresión dar de pasada que traduce 'passer outre, fermer les yeux sur les mauvaise conduite, la désobéissance, les manquements d'autrui, n'en pas garder rancune, faire preuve de tolérance, d'indulgence'.

207 Vid. nota siguiente.

${ }^{208}$ Escrito סודיטי sodete, probable error de dálet por reš. Nehama s.v. sorear (cfr. tc. sür-) recoge la expresión sorear parás que traduce 'dépenser, gaspiller de l'argent', y s.v. sorreteár traduce 'vadrouiller, vagabonder'. Es decir, que el complaciente esposo le da dinero a su mujer, bien para que se lo gaste jugando, bien para que se pase el día paseando por las calles.

${ }^{209}$ Es decir, que todos pueden tomar como ejemplo, en el que todos se pueden basar. 
la mañana beberé café enjuntos, no durará más de diez puntos ${ }^{210}$.

15 Vendré a comer con ella a mediodía por carezar a mi famía; la tadre la llevaré a pasear cuando al cinemá, cuando al Garden Bar ${ }^{211}$.

16 Y la noche la llevaré al balo, anque no sé bailar y quedaré como el palo. Sobre esto vos puedéš siempre baśar, vos rogo no me toméš de naźar ${ }^{212}$.

17 Porque, si demandí vente mil de contado, es porque so un joven bien afamado: estó empiegado como escribano, lo que proba que no so vano.

18 Y gano 40 liras al mes aparte de regalos en cada vez ${ }^{213}$. Espero tomarán en consideración esta mía juusta propośición.

19 Y me darán una novia a mi lado con las 20 mil de contado.

\section{Lo que diće una demuaśel}

20 Vos vo mostrar mi programa de espośar en mostrando mi ropa al baźar ${ }^{214}$. So flaca, alta y hermośa, sé meterme en buena pośa.

21 Conozco todo sorte de cantica y munchos me llaman antica; ḥenośa so hasta el cabo, no tengo del todo cara de nabo.

${ }^{210}$ Es decir, no piensa estar en casa más de diez minutos.

${ }^{211}$ Nombre de un bar de Salónica.

${ }^{212}$ Por lo que dice a continuación de alabanza a sí mismo, quizá quiera decir: no me echéis mal de ojo (tc. nazar).

${ }^{213}$ Es decir, de cuando en cuando.

${ }^{214}$ Es decir, exponiendo mis prendas como si estuviera en un mercado. 
22 Y gillvé tengo demaśía, por mí el joven se haće tequía; amor ya sé haćer a ziedra y a derecha, basta que uno pague su pecha.

23 No digo segunda vez bonsuar a un mancebo sin trabadle el malebịi ${ }^{215}$ y el sebo y no espando a cualquer la mano si con él una pasta no gano.

24 Yo sé haće[r] amor seš većes a la semana, basta que el que me va amar me trate con gana; $\mathrm{y}$, si no me ofre ninguna cośa, yo lo quemo como braśa.

25 El mancebo que escoǵeré puede ser cumarḅás, basta que me lleve a caminar con arabás; no importa si es tembel y borachón, basta que sepa bueno acender el mechón ${ }^{216}$.

$26 \mathrm{Y}$ si sabe yanquesigiilic y ladronicio, para mí será un grande vicio de tener al brazo un hombre de plaza ${ }^{217}$ y no de aqueos jóvenes que arastan como prasa ${ }^{218}$.

27 Todo el que me que[re] por novia que se aderece a mí propia: en Pera ${ }^{219}$, Yoc Ḧan nú' ich y yo le responderé por el quich ${ }^{220}$.

${ }^{215}$ Cfr. tc. mahallebi 'cierto dulce hecho con arroz y leche'; pero, por lo que viene después, habríamos esperado algo así como el tuétano.

${ }^{216}$ Que aquí no parece tratarse del pelo, si no de una mecha gorda; entiendo que quiere decir que el novio debe ser capaz de excitar sus sentidos.

${ }^{217}$ Es decir, hombre de negocios.

${ }^{218}$ NeHAma s.v. prása recoge la expresión fazerse prasa que traduce 'devenir très commun, être à la portée de tout le monde, courir les rues', y s.v. arrastár, arrastar kayes i plasas con el sentido de 'traîner les rues, vagabonder'.

${ }^{219}$ Nombre de un barrio céntrico de Constantinopla.

${ }^{220}$ Pienso que se está haciendo un juego de palabras con la dirección de la joven, y así entiendo que el nombre del edificio (tc. han) es tc. yok 'no, inexistente' y que el número, no es tc üç 'tres' como podría parecer, sino tc. hiç 'no, nada de nada, nunca'. En cuanto a quich podría tratarse de tc. kıç 'nalgas, posaderas, culo'; por su parte Perez-PIMIENTA s.v. (y remitiendo al turco) traducen 'rebuzno' y la expresión entender por el kich como 'entender al revés'. 


\section{El problema DE LAS DOtes}

Ilustro con cinco textos el espinoso asunto de las dotes, del que ya me he ocupado ${ }^{221}$ y del que he vuelto a tratar en mi artículo «Satiras sefardíes».

\section{El ruinoso amor}

El texto procede de la siguiente fuente:

- Versión aljamiada en el manuscrito de Ya‘acob Hazán (Rodas, finales del siglo XIX) f. 10r ${ }^{222}$.

Canción tradicional de la que me ocupo en mi artículo «Cantables», en el que doy bibliografía de otras versiones (pp. 68-75) y estudio su contenido. El texto del manuscrito Hazán lo edita también Attias Cancionero (núm. 38 [B], pp. 107-109: 108-109), en letras latinas y con traducción al hebreo y tras otra versión oral recogida de su madre (en notas señalo mis diferentes lecturas con Attias, ya indicadas en «Cantables»). Attias añade (p. 108) el dato de que la recordaba de su infancia, ya que estaba muy difundida en Salónica en la primera década del siglo XX. Nar Sinagogas (pp. 246-247, con traducción al griego) publica una versión de tres estrofas cuyas primera y tercera son muy similar a las correspondientes de nuestro texto.

Consta de 3 octetas de rima $a b a b c d c d$.

$1 \mathrm{El}$ amor es huerte, huerte y quemador, se mete enfrente ${ }^{223}$ como matador. Chigaricos prontos que vaygan y que venga ${ }^{224}$; muestros padres ganen y que mos mantenga ${ }^{225}$.

2 No es cośa poca lo que vo a ${ }^{226}$ tomar:

${ }^{221}$ Vid. al respecto RoMERo - MANCHEVA «Plagio».

${ }^{222}$ Fecho la canción según las indicaciones de ArmisteAd - SiLVERMAn 3 Calas (p. 16 núm. 12 y p. 21), quienes la atribuyen a la mano III; vid. también ROMERO «Manuscrito Hazán» núm. 12 (p. 244).

${ }^{223}$ AtTIAs dice d'enfrente.

${ }^{224}$ AtтiAs corrige vengan.

${ }^{225}$ AtTIAs corrige mantengan.

${ }^{226}$ AtTIAs omite $a$. 
moneda sin cuenta, groš y ajugar.

Belećico estrecho es dolor de pecho ${ }^{227}$; aḅajo al charší ya ${ }^{228}$ no topo echo.

3 Juguaremos ${ }^{229}$ tavle que es muy hermośo; domino no quero que es caloriośo. Putra me demanda mi hija y mi mujer; mediodía se haće sin haćer sefté.

\section{Niñas sin dote}

El texto procede de la siguiente fuente única:

- Versión oral de Rośina Šemueli (Larissa), publicada por Attias Cancionero núm. 142 (pp. 242-243), en caracteres latinos y con traducción al hebreo.

Según dice Attias (p. 243) el poema se cantaba entre las canciones de amor de principios del siglo XX, precisando que no lo ha oído de ningún otro lugar. Según ello la fecho en ca. 1905. El texto, sin embargo, no suena a canción tradicional, sino más bien a algún poema de autor que la informante hubiera aprendido de memoria.

Consta de 5 estrofas, que son aleluyas emparejadas, más una última aleluya a modo de colofón.

1 Cuatro hijas muy graciosas, como un buqueto de rosas, en un salón se topaban, los sus males racontaban.

2 -Mi papá es mercaderico, no es probe ni es rico;

${ }^{227}$ Que AtTias traduce al hb. por ‘bolsillo’ aludiendo al lugar donde los hombres llevan la cartera.

${ }^{228}$ Eso es lo que leo, pero Attias dice yo.

${ }^{229}$ AtтIAs dice $\hat{J u g a r e m o s .}$ 
si mi hermana se casa

no mantiene más la casa-.

3 -Mi papá es un empiegado, de familla es cargado; ¿qué vo haćer por casarme? Yo cale desesperarme-.

4 -Hay dos años que murió mi padre, al vuestro el Dio que vo lo guadre; no dejó ni un devente ni algún rico pariente-.

5 Estas palabras dićiendo ruido se va oyendo: una boda que pasaba, un rico se casaba.

6 Él tomó novia sin dota, de una buena conducta.

\section{El mal de las dotes}

El texto procede de las cuatro siguientes fuentes:

- A: Versión aljamiada publicada en el libro Cantes populares de Sadic y Gaśóś publicados en El Culebro y La Vara (Salónica, febrayo 1924, edición de La Vara) p. 6 (Havassy New Texts núm. I).- En portada: «... 5. Las dotas»; cabecera: «El mal de las dotas; se canta al son del cante francés "Liśón, Liśet", ${ }^{230} »$.

- B: Versión de fuente oral; publicada en caracteres latinos en «Columna» (p. 29).- Cabecera: «El mal de las dotas; canción popular cantada en distintas versiones en Salónica y Estambul».

- C: Versión de fuente oral cantada por Suśan Mušcatel (Estambul 1911 + Israel 1949) y grabada en Pétah Tikvá (Israel) 1978 por Moshe Shaul ${ }^{231}$.

- D: Versión de fuente oral cantada por Alegría Kasorla (Monastir [Bitola], Macedonia, 1925 + Israel 1950) y grabada en Rišón leŜiyón (Israel) en 1981 por M. S. Sharon ${ }^{232}$.

\footnotetext{
${ }^{230}$ Escrito ליזון ליזיט, fr. «Lisons, Lisette» 'Leamos, Lisette'.

${ }^{231}$ PF 09/1.

${ }^{232}$ PF $107 / 11$.
} 
Poema de Ŝạic y Gaśóś.

Las versiones A y B las he publicado parcialmente en mi libro Entre dos (cap. 10 núm. 82) y aquí las edito completas, en tanto que las versiones $\mathrm{C}$ y $\mathrm{D}$ son inéditas y no las tuve en cuenta en mi libro. Como allí decía, la A también la recoge con mínimos cambios Attias Cancionero núm. 148 (pp. 251-253), en letras latinas y enfrentada a su traducción al hebreo, quien dice (p. 253) que el texto pasó a incorporarse al repertorio tradicional, lo que viene corroborado por las versiones orales B-D y por la precisión que precede al texto B sobre su difusión. Indica además Attias que es posible que sus autores la escribieran antes de las guerras balcánicas, lo que me lleva a fecharla antes de 1912. Por su parte Havassy New Texts (pp. 39-40 y 47-48) comenta el poema y publica fragmentos, enfrentados a su traducción al hebreo ${ }^{233}$. A todo ello podemos añadir una revuelta y breve versión de diez versos que publica Sadikario Raizes (p. 69).

En la versión A consta de 3 estrofas numeradas en romanos de 12 versos de rima $a b a b c d d c d d e e$, seguidas de sendos «Refrén» formados por dos cuartetas de rima $a b a b$. En B está formada por 26 versos en los que es imposible rastrear la estructura original; en C consta de 3 cuartetas de rima $a b a b$; y en D de 6 estrofas de rima descompuesta.

\section{Versión 35.A}

1 Es un grande mal con las dotas, los niños saben aḅuśar; las que non tienen la pilota ${ }^{234}$, ellas non se pueden caśar. Londras y liras demandan los niños; él con fedor al coredor

${ }^{233}$ Conozco aún las siguientes versiones orales que no añaden nada interesante al texto: una de dos estrofas iguales a las dos primeras del número arriba anotado PF 09/1, cantada por Yafa Hazan (Turquía 1920 + Israel 1950) y grabada en Natania (Israel) en 1979 por Camelia Shahar (PF 62/06 ); otra de 4 estrofas: las 2 de antes [ $=\mathrm{PF} 09 / 1]+3^{\mathrm{a}}+4^{\mathrm{a}}=1^{\mathrm{a}}$, cantada por Ester Chiprut (Constantinopla, Turquía 1912 + Israel 1949) y grabada en Bat Yam en 1990 por Zelda Obadiá (PF 326/05); y una más, también de 4 estrofas y basada en las grabadas a Esterica SadikarioMaestro y Bienvenida Manu, ambas de Salónica, y Bela Shabetai, de Skopje (Bulgaria), aparece incluida en el núm. 8 del CD Arboleras vol. 3 de WeICH-SнAнAK (datos en p. [9] y texto en p. [18] del librito que acompaña al CD).

${ }^{234}$ Según el sentido que encontramos en Nehama s.v. pelóta de fazer la pelota 'gagner beaucoup d'argent, s'enrichir faire son magot, sa pelote'; es decir, las que no tienen dinero ahorrado, o como, diríamos, un calcetín. 
les meten a las niñas escariños.

¡Qué dañador!, también el aguador demanda ajugar complet comod y tualet.

La niña la pobereta su alma ve acorar; se haće su cara preta fin a llorar y suspirar.

Sufren bastante los padres por non pueder responder, se pelean con las madres y todo cale vender.

2 Las ricas, miśmo las güelas, todas fuyen de la raźón: quieren dantelas con cordelas, recamada combineźón. Todas quieren stores con priśḅiśes y cašpusier, bailar lancier; non se hartan de pan y bilibiises.

¿Qué dañador! dice el preciador ${ }^{235}$ al ver zamaras y mantó y brodado paltó ${ }^{236}$.

Laźdran la vida entera, se apuran al cośer; sangre non queda gotera para haćer todo haźir.

Camas, también baldaquino, demanda y el hamal $y$ tacum ${ }^{237}$ bueno de lino y velas de pištamal.

${ }^{235}$ Nehama s.v. presyadór explica 'estimateur officiel dont la fonction est de dresser l'inventaire des effets composant le trousseau de la mariée et d'en déterminer le prix'.

${ }^{236}$ Parece que el preciador del ajuar reprueba el despilfarro del mismo.

${ }^{237}$ Nehama s.v. takúm (tc. takım) explica 'ensemble de tous les effets qu'il faut pour habiller quelqu'un, jeu complet de vêtements; parure complète'. 


\section{Los niños quieren meśa franca ${ }^{238}$}

y esfuegro buen paralí;

bušcan la ḥanina ${ }^{239}$ o blanca,

miśmo si él es bragalí ${ }^{240}$.

Non puede pagar la quierá de caśa,

una udá,

el ḥovardá ${ }^{241}$;

¿sabéš en cuálo el musiú se baśa?:

non hay ganar,

cale muncho penar.

Combina y algún tembel

que le pague bedel.

Niños que vaš enỵolvidos,

non sabéš bien escoǵer;

por la dota soš vendidos,

esclavos soš de la mujer.

Bušcad mujer menajera

que sepa bien laborar

con aguja y tijera

y su caśa bien mirar.

\section{Versión 35.B}

Es un gran mal con las dotas,

los mancebos saben abuśar;

las que no tienen la pilota,

ellas nunca se puedrán caśar.

5 Niños que vaš embulvidos, no la sabéš escoǵer;

por la dota soš vendidos, esclavos seréš a la mujer.

Londras y liras demandan los niños

${ }^{238}$ Se refiere a la manutención gratis durante un año o más ofrecida por el padre de la novia a los nuevos esposos.

${ }^{239}$ Que quizá tenga aquí el primer significado que recoge Nehama s.v. janíno 'qui a la peau très blanche'.

${ }^{240}$ Según Nehama s.v. bragalí de braga + sufijo tc. - ll 'individu de basse extraction'.

${ }^{241}$ Es decir, el muy espléndido del novio, no puede pagar ni siquiera el alquiler de una habitación. 
10 y cašpusier ${ }^{242}$, bailar lancier ${ }^{243}$; no se hartan de pan y bilebićes.

¡Qué dañador!, también el aguador demanda ajugar completo,

15 comode y tualet.

Las niñas las poberetas su alma ven acorar, se les haće la cara preta fin llorar y sospirar.

20 Los niños quieren meśa franca y esfuegros bien paralís; bušcan la ḥenośa o la blanca, meśmo si ellos son bragalís. No pueden pagar la quierá de caśa,

25 una udá, el ḥovardá.

Combina y algún tembel que le paguen el bedel.

\section{Versión 35.C}

1 Niños que vaš acorridos, non la sabéš escoǵer; por la dota soš enprendidos, esclavos soš de la mujer.

2 Tomá mujer menajera que sepa bien laborar con la alguja y la tijera y su caśa bien mirar.

3 Está muncho mál esta dota, los niños queren abuśsar ${ }^{244}$ y las que no tienen dota ellas no puedrán caśar.

${ }^{242}$ En nota el editor de la versión indica: «Del francés "cache-poussière", abrigo de seda ligero y fino».

${ }^{243}$ El editor añade entre paréntesis: contradanza.

${ }^{244}$ La informante se corta, la apuntan, oye mal y dice aviśar, vuelve a empezar la estrofa y repite aviśar. 


\section{Versión 35.D}

1 Es un grande mal con la dota los niños saben abusúar; ma las que no tienen la pilota, ellas no se pueden caśar. Londras y liras demandan los niños y con fedor al corredor a las niñas les meten escariño. ¡Qué dañador! diće el aguador al ver zamarras y mantós y brodado paltó.

2 Laźdran la vida entera, se apuran al cośir; sangre no queda gotera para haćer todo haźir.

3 Las ricas ${ }^{245}$ miśmo las güelas todas fuyen de la raźón: quieren tantelas con cordelas, recamada combeneźón.

Todas quieren estores con briśbịiśes y cašcorsé, bailar lancier; no se hartan de pan y belebịiś. ¡Qué dañador! diće el aguador.

4 Sufren bastante los padres por no pueder responder; se peleyan las madres y todo cale vender.

5 Los niños quieren meśa franca y esḥuegro buen paralí; bušcan la ḥanina y la blanca miśmo si él es bragalí. No pueden pagar quierá de caśa, una uda,

${ }^{245}$ Que debería ser chicas. 
miśmo el ḥovardá.

¿Sabéš el [musiú] ${ }^{246}$ en cuálo se aḅaśa?:

no hay ganar,

cale muncho penar.

Combina algún tembel ${ }^{247}$ :

cale pagar bedel.

6 Niños que vaš enỵolvidos,

no sabéš bien escoǵer;

por la dota soš vendidos, esclavos de la mujer.

Bušcá mujer menajera

que sepa bien laborar

con l'aguja y tijera

y su caśa bien mirar.

\section{El novio exigente}

El texto procede de la siguiente fuente única:

- Versión aljamiada publicada en el libro Los cantes populares de Saḍic y Gaśóś (Salónica, abril 1929: edición del Riśón, Imprimería J́ośef Catán) p. 6 (Havassy New Texts núm. VII).- En portada: «...4. דורו דורו [<Dww $d w r w>$ ] (Demanda)»; cabecera: «"Si no me dan tus parientes"; se can-

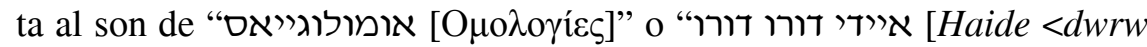
$d w r w>]^{\prime \prime}{ }^{248}$.

Poema inédito de Saạic y Gaśóś. Nar Sinagogas (p. 102) reproduce (con errores) la estr. 2.

Consta de 8 estrofas (precediendo a estrs. 7-8 la indicación «Cuplé» más números de orden 7-8) de 5 versos y rima $x a a y b$ e iniciadas todas por la exclamación $a$ ḥ, que van seguidas de sendos «Refrén» (numerados en arábigos) de dos versos monorrimos. Se repiten los vs. 2 precedidos de haide; se indica bis tras todos los versos 4 (últimos).

1 ¡A Ạ!, si no te da a ti mamá todo bueno y cumplido,

\footnotetext{
${ }^{246}$ Intuyo que eso es lo que dice.

${ }^{247}$ Pero parece decir pember.

${ }^{248}$ Sobre la identificación de la melodía vid. Havassy New Texts p. 94 y Apéndice II p. 192.
} 
caśa montada y salón

y más de un vestido, yo me vo mostrar muy duro, vo falsar mi amor puro.

2 ¡Aḥ!, si no te da a ti mamá mil y quinientas liras, yo el papel ${ }^{249}$ lo vo raśgar, lo haré tiras tiras.

No te mostres anojada, sin parás no vales nada.

3 ¡Aḥ!, si tus hermanos no me dan aníos y manías, yo a ti te vo replazar por el raquí Nahmías ${ }^{250}$.

Tus hermanos son escarsos, tú no cabes en mis brazos.

4 ¡Ah!!, si tu papá no te va dar caśa fecha derecha de la trebde fin la mašá y miśmo y la flecha, siempre ternerás duḅara, tú no vas a ver mi cara.

5 ¡Aḥ!, si tus tíos no me darán empiego algún hecho: una botica de bacal y labor al comercho, yo no vo a ser tu novio, al diablo [el] espośorio.

6 ¡Ah!̣, si la nona no te va dar de la podia guadrada ${ }^{251}$ las perlas para un collar porque hagas parada, yo lo vo quitar a pleito, todo se va yir al viento.

\footnotetext{
${ }^{249}$ Se refiere al contrato de esponsales.

${ }^{250}$ Se trata de una marca de raquí muy apreciada en la Salónica de la época.

${ }^{251}$ En la repetición se suprime el de inicial.
} 
7 ¡A $\mathrm{h} !$, si tu nono no te va dar la parte de la caśa, por esto te vo a deǰar quemada una braśa. Aconseja a tu gente porque me quiten contente ${ }^{252}$.

8 Si esto todo yo terné, tú serás muy querida; presto con ti me caśaré, haremos buena vida. Presto, presto quiero boda antes que pase la moda.

\section{Respuesta al novio exigente}

El texto procede de la siguiente fuente única:

- Versión aljamiada publicada en el libro Los cantes populares de Ŝạic y Gaśóś (Salónica, abril 1929: edición del Riśón, Imprimería J́ośef Catán) p. 7 (Havassy New Texts núm. VII).- En portada: «...7 [= 5]. דורו דורו $[<D w r w d w r w\rangle]$ (Repuesta)»; cabecera: «Cuántas parás vale un novio, repuesta al cante al son de "דורו דורו, $[<D w r w d w r w\rangle] " 》{ }^{253}$.

Poema inédito de Ŝạic y Gaśós; consta de 8 estrofas de 6 versos y rima $x a$ $y a b b$, precedidas por la exclamación $a \grave{\text { h }}$; se repiten los vs. 2 precedidos de haide (salvo en estr. 2); tras todos los versos 4 se indica bis y también tras verso 6 de estr. 1 .

1 ¡A Ạ!, la[s] mientes tienes en papá

y en toda mi ĝente;

sólo vestido y parpar,

no comandas devente ${ }^{254}$;

čharlestón, yacá de cola, tenequiel ${ }^{255}$ y sensa fola ${ }^{256}$.

\footnotetext{
${ }^{252}$ Es decir, para que me tengan contento.

${ }^{253}$ Sobre la identificación de la melodía vid. Havassy New Texts p. 94 y Apéndice II p. 192.

${ }^{254}$ Es decir, no tienes ni un duro.

${ }^{255}$ Nehama s.v. tenekyé explica 'sans le sou, impécunieux'; cfr. tc. teneke 'lata, recipiente de latón'.

${ }^{256}$ NeHAMA s.v. fóla recoge la expresión kedar sin fola que traduce 'rester sans le sou'.
} 


\section{2 ¡Aḥ!, cuando se diǰo espośar echates tapetico $^{257}$; ya te comites tres sermés y hoy bušcas ${ }^{258}$ puntico ${ }^{259}$. Tu quiés parás y no niña para pagar ${ }^{260}$ mucha tiña.}

3 ¡Ah!̣, vienes con harḅ y chalún a todos los de caśa; ya mos tomates por figón, al güevo metes aśa ${ }^{261}$. No sos fijo de Camondo ${ }^{262}$ con dos remendos al fondo ${ }^{263}$.

4 ¡Ah!, ya te hićites benadam ${ }^{264}$, estabas ${ }^{265}$ arastando; ¿tienes cara de demandar que no t'está bastando? Cada día šešit muevo ${ }^{266}$, mos vas a quitar el sebo.

5 ¡Ah! , te lo contienes sin saber, te crees que más vales;

${ }^{257}$ Nehama s.v. tapét recoge la expresión ečar tapet que traduce 's'éterniser en un lieu, paraître résolu à ne pas s'en aller [...]'; alude a que el novio se pasa el día en casa de sus futuros suegros comiendo a la sopa boba.

${ }^{258}$ Dice bušcar.

${ }^{259}$ Es decir, y hoy le buscas los tres pies al gato.

${ }^{260}$ Escrito פאג'אר, que supongo un error gráfico por pagar ya que la palabra tiña que sigue tiene aquí el sentido de 'deuda'; vid. NeHAMA s.v. tíña la expresión kitar tiñas 'payer de vieilles dettes'.

${ }^{261}$ NeHAma s.v. áza recoge la expresión que explica 'recourir à des arguties, à des subtilités; [...] chercher à persuader avec des sophismes, des arguments artificieux, spécieux; chercher des difficultés là où il n'y en a pas, chercher midi à quatorze heures'.

${ }^{262}$ Nehama s.v. Kamóndo identifica al personaje con el conde Abraham de Camondo (17851873), rico banquero de Constantinopla, y recoge la expresión es de Kamondo que traduce 'il se croit être un très grande personnage dérivant d'une haute ligne [...]', como si dijéramos que se cree descendiente de la pata del Cid.

${ }^{263}$ Es decir, que tiene remendados los fondillos del pantalón.

${ }^{264}$ NeHAma s.v. benadám recoge la expresión fazerse benadam que traduce 'devenir un homme comme il faut, s'affiner'; el cambio se ha debido al dinero del suegro.

${ }^{265}$ En la repetición del verso dice estaban.

${ }^{266}$ PeREZ - Pimienta s.v. sheshit, recogen la expresión kitar sheshit muevo que traducen 'salir con un nuevo modelo'; cfr. tc. çeçit 'conjunto; variedad'. 
la peśas para la vender oro a meticales ${ }^{267}$.

A trenta liras la drama vo lo tomáš en el alma ${ }^{268}$.

6 ¡A A !, los mancebicos de el dor todos tienen sus mañas; las londras también las drahmes les parecen castañas. Mirando ${ }^{269}$ al más diablo empeñados por el nablo ${ }^{270}$.

7 ¡A Ạ!, miraldos después de caśar que les caye la goma ${ }^{271}$; parecen viejos sin edad y aniím de Roma ${ }^{272}$. En mancebos son leones, se caśan, son macarones.

8 ¡A A ! , son pocos los que hay de ver ${ }^{273}$, se contan con el dedo que son fidel a la mujer, de estos no hay miedo ${ }^{274}$. Cale tomar al qu'es puro, el restante al monturo.

${ }^{267}$ NeHAmA s.v. metikál explica la palabra 'mesure de poids turque valant une drame et demie ou grammes 4,80 , dont on se sert pour l'or, les perles, etc'. Se me escapa el sentido de la frase ya que no veo claro a qué o a quién se refieren los $l a$ del verso anterior; quizá haya que entender que eso que quiere vender piensa hacerlo con cuentagotas, poco a poco.

${ }^{268}$ NeHAMA s.v. álma recoge la expresión tomar en el alma que traduce 'entraîner quelqu'un, par ses conseils, par son insistance, par son exemple, etc., dans une entreprise néfaste (perte d'argent $[\ldots]$ )'; aquí parece ser que es el novio por sí mismo quien pierde dinero, quizá por gastar demasiado.

${ }^{269}$ Gerundio con valor de imperativo.

${ }^{270}$ NeHAMA S.v. návlo indica como etimología ngr. vaû̉o y recoge esta misma expresión que explica 'être criblé de dettes et n'avoir pas le premier sou pour s'en acquitter'.

${ }^{271}$ Perez - Pimienta s.v. goma y amén del obvio significado de 'goma, gomina', recogen también el sentido de 'prestigio, autoestima'.

${ }^{272}$ Nehama s.v. aní recoge la expresión aniyim de Roma que explica 'gens réduits au dernier degré de la misère [...]', atribuyendo su origen a la pobreza extrema en la que estaban sumidos los judíos del Trastevere romano, donde se encontraba el gueto de la ciudad.

${ }^{273}$ Nehama s.v. ver recoge las expresiones ay de ver y no ay nada de ver que traduce, respectivamente, 'c'est digne d'être vu' y 'cela ne présente rien qui vaille la peine d'être vu'.

${ }^{274}$ No me queda claro el sentido del verso. 
7. LA VIDA FAMILIAR TRAS LA BODA

Y finalmente ilustro el último apartado con solo dos textos de los muchos que podrían aducirse ${ }^{275}$.

\section{Suegras contra nueras}

El texto procede de la siguiente fuente única:

- Versión oral cantada por Alegría Kasorla (Monastir [Bitola], Macedonia, 1925 + Israel 1950) y grabada en Rišón leŜiyón (Israel) en $1981^{276}$.

Canción tradicional inédita, que fecho por aproximación antes de 1910. Consta de 6 cuartetas de rima $a b a b$; tras estrofas 3 y 6 se dice «bam».

1 Entre suegras y nueras siempre hay sehoró y de modos y maneras se peleyan en sirá.

2 La esḥuegra cada día bušca de comandar; su nuera la embía: «Vate en otro andar».

3 El hombre eñervado no sabe a quén juźgar; ma su mujer algo le dio y papá dio parás al hogar.

4 Tiene mañas demudadas, ¡qué dañador!, mancebas y aidadas tienen fidor.

5 Ya no sabe el marido a quién juúgar; siempre él es piedrido, debe pagar.

6 Por su madre criado, ella lo grandició; ma su mujer algo le dio y papá dio parás al hogar.

${ }^{275}$ Vid., por ejemplo, el que publico en mi libro Y hubo luz núm. 1.

${ }^{276}$ PF 106/5. 


\section{Desdichas de un recién casado}

El texto procede de la siguiente fuente única:

- Versión aljamiada publicada en Cantes populares de Ŝạic y Gaśóś publicados en El Culebro y La Vara (Salónica, febrayo 1924: edición de La Vara) p. 11 (Havassy New Texts núm. I).- En portada: «... 10) Postemas de un rećén caśado»; cabecera: «Postemas de un rećén caśado que tomó muchas londras de dota; se canta al son del hermośo cante turco "La Madelón ג'ימאדאג'ים [> gyymadaĝym>]"».- Al pie del texto y tras el seudónimo de los autores se indica: «copia conforme Čharlemañ».

Poema inédito de Saḍic y Gaśós. Havassy New Texts (p. 54) comenta, reproduce y traduce al hebreo algunos segmentos.

Consta de 5 bloques de $6,14,14,14$ y 8 versos, respectivamente; precede a bloques 2-5 la indicación «Refrén».

1 No vo lo quiero contar, no se puede somportar; vos va parecer mantar: si salgo a caminar al Parc o a Bešchinar ${ }^{27}$ ella me haće penar.

2 Estó beźer, piedro el plaćer; lo que me demanda no lo puedo haćer.

Al Panteón, ande Penchik ${ }^{278}$ le trato un Cric ${ }^{279}$ ¡qué biźayón ${ }^{280}$ !: es Yuź Achic ${ }^{281}$, quiere Al Dancic ${ }^{282}$.

${ }^{277}$ Nombres de dos famosos parques de Salónica.

${ }^{278}$ Nombres de otros lugares de Salónica.

${ }^{279}$ Cierta marca de cerveza.

${ }^{280}$ Escrito ביזאייון; cfr. hb. בזיון 'vergüenza, oprobio'.

${ }^{281}$ La primera palabra quizá se trate de tc. yüz 'cara, superficie'; y la segunda puede ser tc. $a c ̧ \imath k$ 'de color claro'.

${ }^{282}$ La palabra al podría tratarse de tc. al 'rojo' y la segunda, escrita דאנסיק, no sé lo que es. Tanto estas palabras como las del verso anterior podrían tratarse de nombres de marcas de cerveza, de ahí mis mayúsculas. En cualquier caso, lo que quiere decir es que si le trae un tipo de cerveza, ella quiere otro diferente. 
¿Quien me ve con saltanat?:

de mi mujer sé alat ${ }^{283}$,

ya non me dejó tacat ${ }^{284}$.

Ella me sabe gormar ${ }^{285}$ :

le plaće baños de mar ${ }^{286}$, invierno quiere comar.

\section{Es negro mal:}

quiere pištamal;

ella me comanda

más negro de hamal ${ }^{287}$.

Estó folón, sin pantalón,

como delinĝ́í;

su źepelín en el čheślón ${ }^{288}$

ya es birinĝ́ ${ }^{289}$.

Yo, que so un albananés ${ }^{290}$,

cuando estó sin penés ${ }^{291}$

quiere peje mayonés ${ }^{292}$...

Yo, a mal de mi peśar,

por źorlá ${ }^{293}$ la vo beśar;

no me deǰa repośar.

${ }^{283}$ NehAma s.v. alát recoge la expresión tomar a uno por alat que traduce 'se servir de quelqu'un comme homme de paille', es decir, que es un pelele en manos de su mujer.

${ }^{284}$ Nehama s.v. takát recoge la expresión no dešar takat sano a uno que traduce injurier quelqu'un en passant en revue toutes ses particularités [...], dénigrer toutes les particularités qui le caractérisent, sans lui faire grâce d'aucune'.

285 NeHAMA S.v. gormár y sin indicar etimología traduce 'infliger des souffrances, des tortures'; por su parte BUNIS Lexicon núm. 912 pone la palabra en relación con la raíz hb. . $\square \cdot 7 \cdot \lambda \cdot r \cdot m$ 'causar' y la traduce 'to suffer, get into an unpleasantness'; cfr. tb. tc. k1r- 'golpear, herir; matar'.

${ }^{286}$ Eso en verano, claro.

${ }^{287}$ Es decir, peor que si fuera un cargador del muelle.

${ }^{288}$ Se me escapa el sentido del verso, como no sea que con źepelín esté aludiendo al culo de su señora; la primera palabra también puede leerse so 'soy'.

289 Tc. birinci 'el primero'; quizá quiera decir «lo más importante».

${ }^{290}$ Que aparte de lo que se entiende a primera vista de albanés, no sé si tiene otro segundo significado.

${ }^{291}$ Es decir, sin un céntimo.

292 Parece decir que, cuando el marido está sin un duro, a la mujer le apetecen los platos más caros, como ese pescado con mayonesa.

${ }^{293}$ NeHAMA s.v. zorlá recoge la expresión por zorlá que traduce 'sans que cela corresponde à un besoin, à la réalité'. 
4 ¡Aḥ!, ¿qué va ser?:

al amanecer

ella me contenta,

me sabe vencer.

Quiere salón ${ }^{294}$, también chayilic

de el javirĝ́i;

yo so burlón: merco liḅric

de el esquiĝ́í.

A moros me sé vender ${ }^{295}$,

no la puedo defender

el chapeo bayader ${ }^{296}$.

Quiere notas de piano ${ }^{297}$ :

sabe tañer, bavonó ${ }^{298}$...,

el suyo y otro no ${ }^{299}$.

5 Sé profitar

y al despertar

la ĝilvéś que tiene

me sabe matar.

Mi violón hago sonar:

le plaće la... yoź.

Como balón y sin penar

m’exita su poś.

[Ya publicada la primera parte de este artículo he advertido el error de presentar mis núms. 11 Viejas a la moda y 23 Los señoritos y las criadas como inéditos, cuando los había publicado Leonor CARRACEDO en su artículo «Canciones sefarditas del tiempo de Juan Chabás», en la revista Dianivm 4 (1989, Homenaje a Juan Chabás) pp. 233-257: pp. 253-255 y 243-244 y respectivamente.]

${ }^{294}$ Quizá muebles para el salón.

${ }^{295}$ Expresión que no sé lo que significa.

${ }^{296}$ Cfr. esp. bayadera, fr. bayadère, probablemente aquí con el sentido que tiene también la palabra en fr. de 'tejido con listas multicolores'.

${ }^{297}$ Es decir, partituras.

באב'ונו Escrito; cfr. hb. בעוונות ba 'avonot 'por (nuestros) pecados, Dios nos libre', según lo cual hay que entender que la mujer toca muy mal.

${ }^{299}$ Parece que quiere decir que sólo sabe tocar una única pieza. 


\section{GLOSARIO}

abocatos (it. sing. avvocato) 'abogados' acavidar 'advertir'; acavidarse 'tener cuidado, ser precavido' acenderse 'encenderse' acetar (it. accettare) 'aceptar' achac 'pretexto' Achic: vid. nota 281 aciduric: vid. nota 28 acorar(se) 'angustiarse' acoridos 'azacanados, angustiados' adererezarse (fr. s'adresser) 'dirigirse' aferada: vid. nota 85 afito: vid. nota 176 aflacarse 'debilitarse' ajustar (fr. ajouter) 'añadir' Al: vid. nota 282 alat (tc. alât) 'instrumento, herramienta'; vid. nota 283 aletric: vid. electric alhad 'domingo' ališic (tc. alışı): vid. nota 75 altelic (tc. altılık): cierta moneda turca alterearse 'darse al libertinaje', 'rebelarse' amá (tc. ama) 'pero'; vid. tb. ma amán (tc. aman) '¡oh!, ¡ah!, ¡socorro!' amanado 'a mano, al alcance de la mano' amator: vid. nota 131 ambeźar(se) 'aprender' ambra (it. ámbra) 'ámbar' andar (cfr. prt. andar 'suelo, pavimento') 'piso, casa' angagée (fr. sing. ms. engagé) 'cogidas del brazo' angajar (fr. engager) 'coger del brazo' 'Aní (hb. עני) 'pobre' aniím (hb. עניים 'aniyim) 'pobres' antarís (tc. anteri, entari): vestido, traje suelto, especie de toga sin mangas cuyos faldones se cruzaban por delante antredós (fr. entre-deux) 'entredós, tiras bordadas'; vid. tb. nota 52 aparadas 'de punta, tiesas' apercantado 'encantado, embrujado' apuntar 'coser, sujetar' 
araḅás (tc. sing. araba) 'carruajes, carrozas, coches de caballos'

arescuñar 'rascar, arañar'

asiento 'nalgas', aquí 'fondillo de los pantalones'

atirar (fr. attirer) 'atraer'; atirarse (fr. s'attirer) 'procurarse, granjearse, conseguir'

atornar (cfr. it. attornáre) 'volver, regresar'

atrayos (cfr. fr. attrayant) 'atractivos'

aver (hb. אוויר avir) 'aire'

bacal (tc. bakkal) 'tendero'

bagdadí: vid. nota 24

baguet: vid. nota 132

balaḅayas (hb. sing. בעלת הבית bá 'alat habáyit) 'mujeres de su casa, esposas' baladós (fr. baladeuse): tipo de tranvías llamados jardineras.

balo (it. bállo) 'baile'

balón (fr. ballon) 'globo'

basmal: vid. nota 57

bavonó: vid. nota 298

bayader: vid. nota 296

baźar (tc. bazar) 'mercado'; haćer - 'regatear'

bedel (tc. bedel) 'impuesto de exención del servicio militar'

belećico (tc. bel 'cintura') 'cinturita'

belino (it. bello) 'guapito'

belo (it. bello) 'bello, hermoso'

bembrillo 'membrillo'

benadam: vid. nota 264

benuar (fr. baignoire) 'palco de platea'

berés (fr. sing. béret) 'boinas, gorras'; vid. tb. nota 149

be[]uta: vid. nota 202

birinĝ́: vid. nota 289

berís (hb. sing. ברית berit) 'circuncisiones (y la fiesta familiar que las acompaña)'

beš (fr. beige) 'de color marrón claro'

beśés: vid. nota 152

betón (tc. beton) 'hormigón'

bey (tc. bey, beğ) 'señor, caballero', 'persona importante'; título honorífico dado a personas al servicio del sultán y del gobierno

beźer (tc. bez- 'cansarse, hartarse'): estar -, haćerse - 'no poder más, descorazonarse, estar harto'

bijuquilas (cfr. fr. bijou 'joya, alhaja') 'joyitas, encantos, preciosidades' 
bilibisies, belebiś (tc. sing. leblebi) 'garbanzos torrados'

biondas (it. sing. bionda) 'rubias'

biźar (fr. bizarre): vid. nota 29

biźayón (hb. בזיון) 'oprobio, vergüenza'

blac botón (ing. black bottom): cierto tipo de baile, similar al claqué, que se caracteriza por el golpeteo que el bailarín realiza con la punta y el tacón de los zapatos, reforzados por unas láminas de metal

blondas (fr. ms. sing. blonde) 'rubias'

blu (ing. blues, esp. blues): cierta forma musical americana

bodras: vid. nota 129

bogos (tc. sing. bo $\breve{g}$ 'bulto, fardo'): vid. nota 39

bolgelic (tc. bol, bolca 'bastante amplio o abundante') 'abundancia, holgura'; tener $a$ - 'tener en abundancia', vid. nota 39

boliśa (cfr. tc. bola 'mujer del tío paterno', bula 'hermana mayor') 'señora, mujer, esposa'

bombé (fr. bombé) 'abombado'

bonhor (fr. bonheur) 'felicidad'

bonjur (fr. bonjour) 'buenos días'

bonsuar (fr. bonsoir) 'buenas tardes'

boy (tc. boy) 'estatura, altura'; vid. tb. nota 35

boya, boyas (tc. sing. boya) 'pintura(s)'

boyaes: vid. nota 164

boyaĝí (tc. boyacı) 'limpiabotas'

bragalí, bragalis: vid. nota 240

brančh (fr. branche) 'ramo, tipo, clase'

briśbiśes, priśbiśes (fr. sing. brise-bise) 'visillos'

broderí (fr. broderie) 'bordado'

brodós (fr. brodeuse) 'bordadora'

bros (fr. brosse 'cepillo'): a la —: tipo de corte de pelo con el cabello muy corto, como un cepillo

bruta (it. brutta) 'fea'

budaca: vid. nota 203

budras: vid. pudra

bufé (fr. buffet) 'ambigu'

buigo 'bullo, cuezo'

buqueto (fr. bouquet) 'ramo'

burino: vid. nota 70

burnú: vid. nota 72

buró (fr. bureax) 'oficina'; vid. tb. nota 115

burracado 'aburacado, agujereado' 
cabaré (fr. cabaret) 'cabaret, sala de fiestas'

cachar (it. cacciare) 'perseguir para dar caza, buscar con ahínco'

cachetas 'rubores, sonrojos'; vid. nota 111

cajaretas: vid. nota 96

caler 'tener que, ser necesario

calorifé (fr. calorifère) 'estufa, calorífico'

calvasará: vid. nota 20

calzas 'medias'

camés: vid. nota 114

campión (it. campione) 'patrón, modelo, muestra'

canones (fr. sing. canon) 'cañones'

canso 'cansado'

cantón 'rincón, esquina'

capán (tc. kapan) 'mercado cubierto'

capotos (fr. sing. capot, tc. kapot, kaput, src. kaput) 'abrigos gruesos, capotes'

carabalic (tc. kalabalık) 'multitud, muchedumbre, gentío'

caré (fr. carré 'cuadrado') 'escote'

carés de lancier (fr. sing. carré, quadrille de lanciers) 'lanceros' (cierto tipo de baile parecido al rigodón)

carezar (fr. caresser) 'acariciar'

carišic (tc. karışık 'mezclado, en desorden; complicado', y karışılık confusión; desórdenes') 'lío, follón, mezcla'

cašcoles (fr. sing. cache-col) 'bufandas'

cašcorsé (fr. cache-corset) 'cubrecorsé'

cašpusier (fr. cache-poussière) 'guardapolvo'

cašterear 'mezclar, entremezclar, entrelazar'; vid. nota 112

cavané (tc. kahvehane) 'lugar para beber café'; 'taberna'

cavás (tc. kavas) 'gendarme, guardia': vid. nota 146

cavé (tc. kahve) 'café'

cavśo: haćer - 'poner problemas, reclamar'

caźic (tc. kazık 'suplicio, tortura'): tomar — 'sufrir tortura'

čena (it. scena) 'escena'

chalguí (tc. çalgl) 'instrumento musical', 'música instrumental'

chalguiĝ́is (tc. sing. çalgıcı) 'músicos, banda de música'

chalún (tc. çalım) 'aplomo, dignidad; arrogancia, jactancia, fanfarronería'

čharmantes (fr. sing. charmant) 'encantadores'

čharpas (fr. sing. écharpe) 'corbatas, pañuelos, echarpes'

charší (tc. çarşı) 'mercado' 
chayilic (cfr. tc. çay 'te') 'juego de te'

čher (fr. cher) 'caro'

čheślón (fr. chaise longue) 'hamaca, tumbona'

chibuc (tc. çubuk) 'pipa'

čhic (fr. chic) 'elegancia, buen gusto'

chicur: vid. nota 88

chigaricos 'cigarritos, puritos'

čhimís (fr. chemise) 'camisa'

chisé (tc. köşe) 'rincón, esquina'

choca: vid. nota 109

chocas: vid. nota 37

cholaca (tc. ms. çolak) 'manca'

čhomaǵe (fr. chômage) 'paro, desempleo'

cinemá (fr. cinéma) 'cine'

cločh (fr. cloche, tc. kloş) 'acampanada'

coda (it. coda) 'cola'; vid. tb. nota 95

colana: vid. nota 79

comar (tc. kumar): cierto juego de dados

comarbás (tc. kumarbaz) 'jugador, tahur'

combinar 'idear, tener una ocurrencia'; - que 'suceder que, ocurrir que'

comod (fr. commode) 'cómoda, tocador'

complet (fr. complet) 'completo'

conbineźón (fr. combinaison, tc. kombinezon) 'combinación', prenda de ves-

tir femenina sobre la ropa interior y debajo del vestido

condanarse (fr. se condamner, it. condannarsi) 'condenarse'

condurias (tc. sing. kundura) 'zapatos'

conquerencia (cfr. fr. conquérir) 'conquista'

conseja 'cuento, fábula'

consentir un dolor 'sufrirlo, padecerlo'

contado: parte de la dote que se paga en dinero

contarse 'considerarse'

contenerse 'presumir, tenérselo creido'

contrabaso (it. contrabasso) 'contrabajo'

corbey (fr. corbeille de mariage) 'canastillo de boda, ajuar'

corcobada 'jorobada'

cordelas (tc. sing. kordela, kordele, kurdela) 'cintas'

coredores 'casamenteros'

corejar 'corregir'

corsos (it. sing. córso) 'paseos, calles, avenidas' 
costreto (it. costretto): ser - 'estar obligado, constreñido'

creda 'cera'

criś, criśa (fr. crise) 'crisis'

cronic (fr. chronique) 'crónico'

cuafada (fr. coiffée) 'peinada'

cuafur (fr. coiffeur) 'peluquero'

cuantos 'muchos'

cuclas (tc. sing. kukla, ngr. sing. коик $\lambda \alpha$ ) 'muñecas'

cudurear (tc. kudur-) 'divertirse con locura, hacer el loco'

culada 'colada'

culetu (it. colleto, esp. coleto) 'cuello postizo'

cumplición 'normas de conducta'; vid. tb. nota 157

curear: vid. nota 145

cutís (tc. sing. kutu) 'cajas'

dactilos (fr. sing. dactylo) 'mecanógrafas'

dalavera (tc. dalavera 'trampa') 'locura, desenfreno, calaverada'

Dancic: vid. nota 282

dancing, dancingues (fr. sing. dancing, ing. sing. dancing) 'sala(s) de baile, sala(s) de fiestas'

dansós (fr. danseuse) 'danzarina, bailarina'

dantelas, tantelas (tc. sing. dantel, dantelâ, fr. sing. dentelle) 'puntillas'

dañador 'maldad, perversión'

debúčch (fr. débauche) 'exceso, desenfreno'

decolté (fr. sing. décolleté) 'escotes'

dediez: nombre dado a una moneda turca de poco valor

defender (fr. défendre) 'prohibir'

demarčhes (fr. sing. démarche) 'pasos, gestiones'

demaśiado: vid. nota 166

demuaśel (fr. demoiselle) 'señorita'

demudados 'raros, extraños; inconvenientes'

deranjar (fr. déranger) 'molestar, importunar'

dernier-fasón (fr. dernière fashion, dernière façon) 'última moda'

dert (tc. dert) 'pena, sufrimiento, preocupación, angustia'

descoridos 'arruinados'

deśmodrados 'disparatados, alocados'

deśmodramiento 'hábito insólito, disparatado', 'vicio'

despechośa 'despectiva'

devenir 'convertirse' 
deventes: nombre dado a una moneda turca dilinĝ́ (tc. sing. dilenci) 'pobres, mendigos' dirito (it. diritto) 'derecho' diśgustante (cfr. fr. dégoûtant) 'asqueroso, repugnante' dober (it. dovére): $a$ - 'bueno, como debe ser, convenientemente' dopio (it. doppio) 'doble'

dor (hb. דור 'generación'): mancebicos del -, niños(a) del — 'chicos(a) modernos(a)'

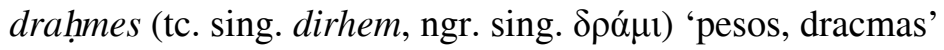

drezar: vid. nota 133

dubara (tc. dubara 'trampa', 'intriga') 'tumulto, revuelo, alboroto, estrépito' duḅlé (fr. doublé) 'forrado'

duź (tc. düz) 'liso; derecho; sin adornos'

ediques (tc. sing. edik): tipo de botas suaves y cómodas para andar por casa Egé (fr. Égée) 'Egeo'

electric, aletric (fr. électrique) 'eléctrico'

embeźar 'aprender'

empiegado (it. impiegato) 'empleado'

empiego (it. impiego) 'empleo'

emprestar 'tomar prestado'

empretecer 'ennegrecer, teñir de negro'

encañar 'ensuciar'

encorajar (fr. encourager) 'animar, alentar'

enfornar, fornar 'hornear'

engrobiñar 'estrujar, refregar, frotar'

enjaguar 'enjuagar, aclarar'

enpudreadas '(cfr. fr. poudre 'polvo') 'empolvadas, maquilladas'

enramar: echarse a'enramar 'buscar pelea para obtener más de lo debido, extorsionar'

ensuña 'rencor, resentimiento'

enterar 'enterrar'; vid. nota 126

entojos: vid. nota 77

eñervado 'enfadado'

escapar 'terminar'

escarpicas (it. sing. scarpíno) 'escarpines (dim.), zapatitos de baile'

escarsos (it. sing. scarso) 'avaros'

escorchar (fr. écorcher, it. scorticare) 'despellejar'

eśmerzar (ct. esmerçar, it. semerciáre) 'comprar, vender, hacer negocios' 
espandir 'tender (la ropa)'

esponjar 'fregar'

esprito (fr. esprit, it. spirito) 'espíritu'

esquiĝ́ (tc. eskici) 'ropavejero'

eśvariar 'perder la cabeza, volverse loco'

evropeo 'europeo'

exantric, exantrís (fr. sing. excentrique) 'excéntrico(s)'

expośar (fr. exposer): haćer - 'exponer'

facha (it. faccia, tc. faça) 'cara'

fácile (it. facile) 'fácil'

faldar 'faldas'

far (fr. fard) 'pintura, afeite'

fardarse (fr. se farder) 'maquillarse, afeitarse'

fasón (fr. façon) 'manera'

fedidos 'arrogantes, soberbios'

fedor, fidor 'arrogancia, orgullo, soberbia'

felec (tc. felek 'destino, hado') 'mundo, época; actualidad', 'moderno'

ferahlic (tc. ferahlik) 'comodidad, tranquilidad'

fieros (fr. sing. fière) 'orgullosos, altivos, altaneros'

fierro: dar - 'planchar'

filmo (fr. film) 'película'

fin, fin a 'hasta'

fiongos (ngr. фiovyos) '(sombreros) hongos'

fiubas (it. sing. fibbia) 'bucles, rizos'

flatar (fr. flatter) 'halagar, adular'

flecha 'rodillo de amasar'

fločh (fr. floche) 'aterciopelada'

folón (cfr. fr. failli) 'arruinado'

fornar: vid. enfornar

fostanas (tc. sing. fistan, esp. sing. fustán) 'vestido femenino'

fox, fox-trot, foxs-trot, foxtrotes, foc-strot (ing. sing. foxtrot): cierto tipo de baile

foyas 'hoyos; hoyuelos (de la cara)'

franco 'francés, occidental'

Franquía 'Francia', tb. 'Occidente'

fregar (it. fregáre) 'frotar, restregar, dar masajes'

friśadas (cfr. fr. sing. ms. frisé) 'rizadas, con el pelo hecho la permanente' frišés (cfr. fr. sing. ms. frisé) 'permanentes, bucles' 
frivol (fr. ms. frivol) 'frívola' fucará (tc. fikara, fukara) 'pobre, mendigo' fustas (tc. sing. fistan, esp. sing. fustán) 'enaguas'

gambas (it. sing. gámba) 'piernas'

gancho 'anzuelo'

ganeden: vid. nota 101

garbe 'garbo'

garniźón (fr. garnison) 'guarnición, adorno que se pone en las prendas de vestir' garzón (fr. garçon 'chico, joven'): a la —: vid. nota 30

gavienta (hb. ms. גאוון gaaván) 'orgullosa'

genar (fr. gêner) 'molestar, incomodar'

gentilhom (fr. gentilhomme) 'hidalgo, gentilhombre'

gep (tc. cep) 'bolsillo'

gilvé, gilvés, gillvés (tc. sing. cilve) 'gracia(s), encanto(s), coquetería(s)'

ginollos (cfr. it. sing. ginocchio) 'rodillas, hinojos'

giro (tc. çiroz 'caballa seca y salada') 'persona muy delgada'

goma: vid. nota 271

gormar: vid. nota 285

grandicer 'criar, educar, engrandecer'

groš (tc. guruş, kuruş) 'piastra'

grutas 'tiendas'

guán step, un-step, uán stepes (ing. sing. one-step): nombre de cierto baile de salón

guay 'ay'

guayar 'lamentarse, llorar'

guebir (hb. גביר) 'rico; persona importante'

güelas 'mujeres mayores, abuelas'

güerco 'el ángel de la muerte'

guetres (fr. sing. guêtre) 'polainas'

hִaber (hb. חבר) 'compañero, amigo; novio'; vid. nota 87

habil (fr. habile) 'hábil'

hadras 'gestos, ademanes, aspavientos'

hadrośos 'amanerados, afectados, estirados'

halcá (tc. halka) 'anillo, zarcillo'

haločentas 'una fortuna, tropecientas'

hamal (tc. hamal) 'cargador, porteador, mozo de cuerda

han: vid. nota 49 
handrajos 'andrajos'

hanina, haninas (cfr. hb. חן 'gracia') 'simpática(s), graciosa(s); rubias, de pìel blanca'

harb (tc. harb) 'combate, pelea'

harbar 'golpear'

hạšǐs (tc. haşiş) 'mariguana'

Havá (hb. חווה) 'Eva'

haviar (tc. havyar) 'caviar'

haźir (tc. hazır) 'preparado, dispuesto'

hec 'he aquí que'

hecho tb. 'negocio; trabajo'

hen (escrito ח ח, hb. ח) 'gracia'

henośa (hb. ח hen 'gracia') 'buena, graciosa, bonita, preciosa'

heśitar (fr. hésiter) 'dudar, vacilar'

hey 'ahí, allí'

horfentos: vid. nota 171

hormar: vid. nota 124

horośos (fr. sing heureux) 'felices, dichosos'

hovardá (tc. hovarda) 'liberal, generoso, espléndido'; vid. tb. nota 241

ich: vid. nota 220

inda 'todavía'

jadés (tc. sing. cadde) 'avenidas, bulevares'

jamleado : vid. nota 66

jamliques: vid. nota 62

jaquet (fr. jaquette) 'chaqueta'

javirĝi (tc. cevahirî, cevherî) 'platero'

J́aźbán (ing. jazz band) 'orquesta de jaz'

jonés (fr. jeunesse) 'juventud'

jóvena (cfr. it. ms. giovane) 'chica joven'

jovenicas 'jovencitas'

jubas: vid. nota 26

juguet (cfr. fr. jouet) 'juguete'

Julí (fr. Julie): nombre femenino; vid. nota 91

labor 'trabajo'

laboro (it. lavóro) 'labor, trabajo'

laćeria 'trabajo, esfuerzo agotador' 
lamé (fr. lamé) 'tisú de oro o de plata'

lancier: bailes de figuras parecido al rigodón; vid. tb. carés

landras: vid. nota 107

laźdrar 'trabajar, esforzarse'

lechón: vid. nota 136

libadé, liḅadés (tc. sing. libâde) 'abrigo(s) forrado(s) de lana o de algodón'

libric (tc. ibrik) 'cafetera, tetera'

lišos 'liso, pulido'

locum (tc. lokum): cierto tipo de dulce

loja (fr. loge, it. lóggia) 'palco; platea, gallinero'

londras 'libras esterlinas'

lonso ('oso; individuo sin educación'): haćerse del —: vid. nota 204

lusos (it. sing. lusso) 'lujos'

lusosas (it. lussuosas) 'lujosas'

lustrín (fr. lustrine): cierto tipo de tejido

lustro (it. lústro) 'lustre, brillo'

$m a$ (it. $m a$ ) 'pero'; vid. tb. amá

madam, madama, madamas (fr. sing. madame) 'señora(s)'

maká: vid. nota 86

Malcá (escrito מאלקה, hb. מלכה Malká 'Reina'): nombre femenino; vid. nota 91

maldar: vid. meldar

malebí: vid. nota 215

malgrado (fr. malgré) 'a pesar de'

mancar (it. mancáre, fr. manquer) 'faltar; dejar'

manco (it. manco) 'menos'

manías 'pulseras'

manicur (fr. manicure) 'manicura'

manidas: vid. nota 154

mantar (tc. mantar [argot]) 'mentira, invención, trola'

mantó, mantós (fr. sing. manteau) 'abrigo, gabán'

manuto: vid. nota 197

mašá (tc. maşa) 'pinzas, tenazas'

mayonés (fr. mayonnaise) 'mayonesa (salsa)'

medán (tc. meydan) 'plaza, mercado'

meldar, maldar 'leer'

menajera (fr. ménagère) 'hacendosa, buena ama de su casa'

mercar 'comprar' 
meticales (esp. sing. metical, tc. sing. miskal): cierta medida de peso; vid. nota 267

metrez (fr. maîtresse) 'meretriz, amante'

miñón (fr. mignon) 'gracioso, lindo, bonito'

molo 'muelle (para atracar los barcos)'

mongrinas (?) 'lloronas, sombrías, melancólicas'

monturo (prt. monturo) 'montón de escombros, vertedero, basura'

mumís: vid. nota 10

munĝir (it. mungere) 'ordeñar'

musandará (tc. musandıra 'alacena') 'buhardilla'

muscles (fr. sing. muscle) 'músculos'

mušos 'labios'

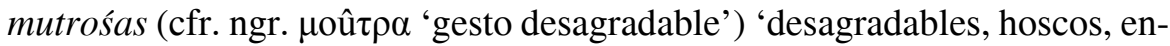
furruñados'

nablo: vid. nota 270

narguilé (tc. nargile) 'pipa de agua'

naźar: vid. nota 212

naźic (tc. nazik) 'refinado, elegante', 'agradable, placentero'

neglijar (fr. négliger) 'descuidar, desatender'

negro 'malo'

nono, nona (ngr. ms. vovvó) 'abuelo', 'abuela'

novlios 'novios'

nur (tc. nur) 'luz, brillo, encanto'

ofrir (fr. offrir) 'ofrecer, regalar'

opium (fr. opium) 'opio'

orejales 'pendientes'

otós (abrev. de fr. sing. automobile) 'autos, coches'; otós blindés (fr. sing. blindé) 'blindado, acorazado'

oyás (tc. sing. oya) 'puntillas, encajes'

pachás (tc. sing. paça) 'piernas'

pajar: vid. nota 260

paltó (tc. palto, fr. paletot) 'abrigo'

panic (fr. panique, tc. panik) 'pánico'

papadas: echar —: vid. nota 105

papilión (fr. papillon 'mariposa') 'pajarita', tipo de corbata pequeña así denominada 
pará, parás (tc. sing. para) 'moneda(s), dinero'

parada: haćer - (calco del fr. faire parade de) 'hacer ostentación, hacer alarde'

paralí (tc. paralı) 'rico, con dinero'

parfum (fr. parfum) 'perfume'

parpar (tc. par par parla - 'resplandecer, brillar') 'apariencia, prestancia'

parvenir (fr. parvenir) 'llegar'

pasar tb. 'estar de moda, estilarse'

pasto 'gusto, sabor'

pátaḥ: vid. nota 114

peás: vid. nota 19

peје 'pez, pescado'

pejes: vid. nota 137

pelizcar 'pellizcar'

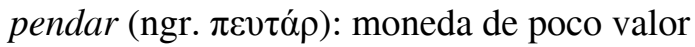

penés (tc. peni, scr. penez, ing. penny) 'moneda de cobre de poco valor'

peros ('perros'): — de boda: vid. nota 94

perpusión: vid. nota 144

pirianas: vid. nota 93

pišín (tc. peşin, pişin) 'inmediatamente, al instante'

pištamal (tc. peştemal) 'vestido ancho', 'toallas grandes de baño', 'cierto tipo de tejido'

pitas (ngr. sing. $\pi \imath \tau \alpha)$ : cierto tipo de panes

platías (ngr. sing. $\pi \lambda \alpha \tau \hat{\imath} \alpha)$ 'plazas públicas'

poberetos, pobereta (it. ms. sing. poveretto) 'pobrecitos, pobrecita'

podia, podias (ngr. sing. $\pi \delta \delta i \alpha$ ): vid. nota 16

polités (fr. politesse) 'cortesía, urbanidad'

polla aquí 'chica joven'

porpurí (fr. pot-pourri) 'popurrí'

portanto (fr. pourtant) 'no obstante, sin embargo'

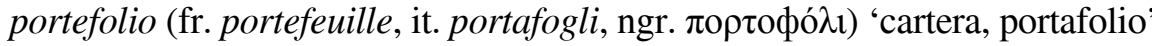

poś, pośa (fr. pose) 'actutud, postura'

potín (fr. bottin, tc. potin, botin) 'botines'

pranzos (it. sing. pranzo) 'comidas, banquetes'

prasa (tc. pirasa) 'puerro'

pretansión (fr. prétention) 'pretensión'

preto 'negro'

priśbisises: vid. briśbiśes

prontas (it. ms. sing. prónto, fr. sing. ms. prompt) 'preparadas' 
puatrín, puatrines (fr. sing. poitrine) 'pecho(os)'

pudra, putra, puder, budras (fr. poudre, ngr. $\pi$ oûf $\rho \alpha$, tc. podra, pudra) 'polvos de cosmética'

pudriduras 'graves preocupaciones'

punchunośas 'puntudas, que pinchan'

puntos 'segundos'

putra: vid. pudra

quedos 'quietos'

questión (fr. question) 'cuestión, discusión'

quich: vid. nota 220

quiebapes (tc. sing. kebap) 'asados'

quiefes (tc. sing. keyif) 'gustos, deseos'

quiemán (tc. keman) 'violín'

quiemer: vid. nota 43

quiepaśilic (tc. kepazelik) 'deshonor, ignominia'

quierá (tc. kira) 'renta, alquiler'

quito 'divorciado'

quiurdí: vid. nota 23

racontar (fr. raconter) 'contar, relatar'

Rahelica (ראחיליקה, dim. de hb. רחל Rahel) 'Raquelita'

ramplazar (fr. remplacer) 'sustituir, remplazar'

raquí (tc. rakl) 'aguardiente'

recamos 'recamados, brocados'

reevarse 'llevarse, estar de moda'

refrén (fr. refrain) 'estribillo'

refuśar (fr. refuser) 'rechazar, rehusar'

regretar (fr. regretter) 'lamentar, deplorar'

regreto (fr. regret) 'pena, pesar, sentimientos de conmiseración'

regular (esp.) 'ajustar, determinar'

rejetar (fr. rejeter) 'rechazar, echar'

remorzos (it. sing. rimorso) 'remordimientos'

rendir (fr. rendre) 'convertir', 'dar, conceder'

reón-ix: vid. nota 27

repotreo 'juerga, diversión'

resfolgar 'descansar, reposar'

resiento 'calma, orden, buenas maneras'

reušir (fr. réussir, it. riuscire) 'tener éxito, lograr' 
revoltante (fr. révoltant) 'escandaloso insultante'

riźá, riźás (tc. sing. rida 'echarpe') 'pañuelo(s)'

rodanchas: vid. nota 147

rolo (fr. rôle) 'papel'

ropa 'mercancía'

roś (fr. rose) 'rosa'

royo 'pelirrojo'

ruḥas 'arrugas'

šabat, sabá: vid. nota 15

saltanat (tc. saltanat) 'pompa, magnificencia, ostentación'

samán (tc. saman) 'paja, heno'

san (fr. sans) 'sin'

san-rival (fr. sans rival) 'sin rival', aunque quizá se trate del nombre de una marca comercial

santimantal (fr. sentimental) 'sentimental'

Sará (escrito סארה, hb. שרה Sará 'Sara'): nombre femenino

saray (tc. saray, seray) 'palacio, mansión'

sarcharse (prt. sarjar 'sajar') 'arañarse'

šarquí (tc. şarkı) 'canción'

šastra 'sastra, modista'

scumpartir: vid. nota 6

sé tb. 'soy'

sefté (tc. siftah) 'primera venta del día que hace un mercader'

seḥorá (hb. שחורה 'negra') 'desgracia'

sensa (it. senza) 'sin'

sensos (it. sing. sénso) 'sentidos, sentimientos'

separés (fr. sing. separé) 'reservados', lugares semicerrados en salas de fiesta

Serbía (cfr. tc. Strbiye) 'Serbia'

sermé, sermés (tc. sing. sermaye 'capital') 'dote(s)'

še ̌̌erear (tc. şaşır-) 'marear'

šešit: vid. nota 266

seśón (fr. saison) 'temporada'

shachar 'romper, aplastar'; vid. nota 139

siécolo (it. secolo) 'siglo'

sirá: a la -, en -: vid. nota 21

šiúr: vid. nota 200

soldo (it. sòldo) 'moneda, dinero' 


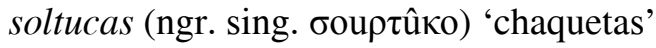

soretar: vid. nota 208

soy (tc. soy 'familia, linaje'): venir de - 'pertenecer a una familia distinguida' stores 'estores'

suá (fr. soie) 'seda'

suarés (fr. sing. soirée) 'saraos, fiestas'

succeso (fr. succès) 'éxito'

sudito (it. suddétto) 'sobredicho, susodicho'

sujé (fr. sujet) 'causa; asunto, tema'

Sunhula (abrv. de hb. שמחה Simhá 'Alegría'): nombre femenino; vid. nota 91 suples (fr. sing. souple) 'flexibles'

sutienes (fr. sing. soutien-gorge) 'sostén, sujetador'

tabá, tabac: vid. nota 8

taburá, taburrá: vid. nota 118

tacat: vid. nota 284

tacum: vid. nota 237

tallas: 'talles, cinturas'

tallator (it. tagliatóre 'cortador'): vid. nota 130

tantelas: vid. dantelas

taquinar (fr. taquiner) 'hacer rabiar, pinchar'

tavle (tc. tavla) 'chaquete', cierto juego

telefón (fr. téléphone) 'teléfono'

telías: vid. nota 69

telipuli (tc. telli pullu) 'engalanados, de punta en blanco'

tembel (tc. tembel) 'perezoso, indolente, vago'

tenequiel: vid. nota 255

tentés: haćer - 'dar los primeros pasos un bebé'

tequía ('tisis, tuberculosis'): haćerse - 'consumirse'

terné 'tendré'

tiñas 'discusiones, problemas'

tiro: $a$ - 'de punta en blanco, de tiros largos'

todra 'tonta, boba'

tram (fr. tram) 'tranvía'

transparán (fr. transparent) 'transparente'

tratar 'ofrecer, invitar, convidar'

trebde 'trébede'

tres: vid. nota 151

trespasar 'pasar de la ralla' 
trincar (cfr. fr. trinquer 'chocar los vasos') 'rechinar' tualet (fr. toilette) 'tocador'

tudesca (fr. ms. tudesque) 'alemana'

tumán (tc. tuman) 'calzones, pantalones'

turnú (fr. tournure) 'miriñaque'

tutó: vid. nota 83

udá (tc. oda) 'cuarto, cámara, habitación'; vid. tb. nota 115

unfladas 'hinchadas'

un-step, uán stepes: vid. guán step

$u t$ (tc. $u t, u d$ ) 'laud'

vandośas (fr. sing. vendeuse) 'vendedoras'

vardar: vid. nota 13

vay (hb. ' ’) ¡ay!

velas 'cortinas'

vero (it. véro) 'verdadero'

versar (fr. verser) 'entregar, dar'

yeśḅas (cfr. it. sing. vespa) 'avispas'

vicio 'placer, gusto'

yierbos 'palabras'

viśar (fr. viser) 'apuntar, fijar la vista, contemplar con atención'

vista: de — 'enseguida, inmediatamente'

volar 'morirse'

vual (fr. voile) 'crespón, tejido delgado y transparente'

$y$ tb. 'también, incluso'

yacá, yacás (tc. sing. yaka) 'cuello(s) camisero(s)'; yaca de cola 'cuello duro' yanquesigilic (tc. yankesici) 'ratero, ladrón, carterista'

Yoc: vid. nota 220

yurmeší (cfr. tc. germeşik o tc. yer meşesi): respectivamente, 'cornejo' y 'especie de teucrio o camedrio'

Yuź: vid. nota 282

źembil (tc. zembil) 'cesto, cesta'

źepelín (fr. zeppelin, esp. zepelín) 'dirigible'; vid. nota 288

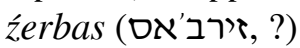

zor (tc. zor) 'dificultad, estrechez; cuestión problemática'

zorlá (tc. zorla- 'forzar, obligar'): por — 'a la fuerza, por obligación' 


\section{BIBLIOGRAFÍA CITADA ABREVIADAMENTE}

Samuel ArmisteAd - Joseph H. Silverman, Tres calas en el romancero sefardí (Rodas, Jerusalén, Estados Unidos) (Madrid 1979): pp. 11-79, «A. El Ms. De Yakov Hazán (Rodas, siglos XVIII-XX) pp. 11-79.

Moshe Atrias, Cancionero judeo-español (Jerusalén 1972).

Baecs: vid. Romero Bibliografía.

David M. BunIs, A Lexicon of the Hebrew and Aramaic Elements in Modern Judezmo (Jerusalén 1993).

—, Voices from Jewish Salonika: Selections from the Judezmo Satirical Series Tio Ezrá I Su Mujer Benuta and Tio Bohor I Su Mujer Djamila by Moshé Cazés (Jerusalem - Thessaloniki 1999).

«Columna en Judeo-Español», Voz Sefaradi 2/18 (nov. 1967) p. 29.

Alberto CONEJERo LóPez, «Cantes satíricos sobre la mujer moderna en Los cantes de La Trompeta y Los cantes de La Gata» (presentado en la « $4^{\text {th }}$ International Conference on Judeo-Spanish Studies», Salónica, 26-28 oct. 2008).

Samuel M. ElazAR, El romancero judeo-español (Romances y otras poesías) (Sarajevo 1987).

José Manuel Fraile Gil - Susana Weich-ShahaK, «Los trabajos de la semana: Congéneres sefardíes, españoles y portugueses», Estudos de Literatura Oral 2 (1996) pp. 125-149.

Rivka Havassy, New Texts to Popular Tunes: Sung-Poems in Judeo-Spanish (Ladino) by Sadik Gershom and Moshe Cazes (Sadik y Gazoz) (Tesis: BarIlan University 2000).

Alberto Hemsi, Cancionero sefardí, Edwin Seroussi (ed. e intr.), colb.: Paloma Díaz-Mas, José Manuel Pedrosa y Elena Romero (Jerusalén 1995).

Isaac Levy, Chants judéo-espagnols, 4 vols. (Londres - Jerusalén 1959-1973) se cita el vol. II.

Michael Molno, Usos y costumbres de los sefardies de Salónica (Madrid Barcelona: CSIC, 1950).

—, «Los faubourgos de Salonique a traverso los siecolos / Hašejunot hayehuyidot beSaloniqui», en David A. Recanati (redactor), Zikhron Saloniki ..., 2 vols. (Tel-Aviv 1972 y 1986): vol. II (1986) pp. 5-31.

Albertos NAR, OI $\Sigma$ YNAГ $\Omega \Gamma E \Sigma$ TH $\Sigma$ @E $\Sigma$ A $\Lambda$ ONIKH $\Sigma$ TA TPAГOY IA MA $\Sigma$ ('Las sinagogas de Salónica ...') (Salónica 1985). 
Joseph Nehama, Dictionnaire du Judéo-espagnol (Madrid: CSIC, 1977).

Avner Perez - Gladys Pimienta, Diksionario amplio djudeo-espanyol - ebreo ... (Israel: La Autoridad Nasionala del Ladino ... - Sefarad - El Instituto Maale-Adumim, 2007).

Elena Romero, «Los cantables de Yosef vendido por sus hermanos», Estudios Sefardies 1 (1978) pp. 65-82.

—, «Coplas sefardíes y textos afines en el Ms. de Yakov Hazán de Rodas», en Michael GerLi and Harvey L. Sharrer (eds.), Hispanic Medieval Studies in Honor of Samuel G. Armistead (Madison: Hispanic Seminary of Medieval Studies, Univ. of Wisconsin, 1992) pp. 243-256.

-, Bibliografía analítica de ediciones de coplas sefardíes, Intr. Iacob M. Hassán, [= Baecs] (Madrid 1992).

—, Entre dos (o más) fuegos: Fuentes poéticas para la historia de los sefardíes de los Balcanes (Madrid: CSIC, 2008).

—, Y hubo luz y no fue tan buena. Las coplas sefardies de Purim y los tiempos modernos: bibliografía, estudio y edición de textos (Barcelona: Tirocinio, 2008).

-, «Sátiras sefardíes salonicenses (con su poquito de misoginia) sobre las elecciones griegas de 1926», ponencia presentada en la «4th International Conference on Judeo Spanish Studies» (Salónica, 26-28 oct. 2008), en prensa para las Actas.

Elena Romero - Dora Mancheva, «Historia de un plagio: las coplas sefardíes Los tiempos modernos, de Sa 'adí Haleví, y El lujo y la escasez, de Ya'acob Yoná», Sefarad 67/2 (jul.-dic. 2007) pp. 437-468.

Avram Sadikario, Raizes (Skopje: ed. del autor, 2006).

Enrique SAPORTa y Beja, En torno de la Torre Blanca (París 1982).

Berta SAVARIEGo - José SÁNchez-Boudy, Vida y cultura sefardita en los poemas de 'La Vara' (del ladino al español) (Miami, Florida: Ediciones Universal, 1987).

Susana Weіch-Sнанак, Arboleras: Cancionero sefardí del siglo XX ..., vol. 3 (CD: Saga, 2000).

—, ¡En buen simán!: Panorama del repertorio musical sefaradí (Haifa: Pardés, 2006).

Recibido: 06/10/2008

Aceptado: 01/05/2009 